\title{
Influence of Ionic Liquid Species in Non-Aqueous Electrolyte on Sodium Insertion into Hard Carbon
}

\section{Minato EGASHIRA,* Tomoyo TANAKA, Nobuko YOSHIMOTO, and Masayuki MORITA}

\author{
Graduate School of Science and Engineering, Yamaguchi University, \\ 2-16-1 Tokiwadai, Ube, Yamaguchi 755-8611, Japan
}

*Corresponding author: minato@yamaguchi-u.ac.jp

\section{ABSTRACT}

The electrochemical insertion and de-insertion of sodium ion in hard carbon has been monitored in electrolytes consisting of sodium perchlorate $\left(\mathrm{NaClO}_{4}\right)$, propylene carbonate (PC), and an ionic liquid $\mathrm{N}, \mathrm{N}$-diethyl- $\mathrm{N}$-methoxyethyl ammonium bis(trifluoromethane sulfonyl)imide (DEMETFSI). Voltammetric observation revealed that the reversible sodium insertion is inhibited by the content of DEMETFSI in the electrolyte. The reversible signs of sodium insertion become obvious when the volumetric content of DEMETFSI was 70\%. The inhibition effect for sodium insertion by DEMETFSI is somewhat in relation to the change in coordination with sodium ion in electrolyte.

(c) The Electrochemical Society of Japan, All rights reserved.

Keywords : Sodium-Ion Battery, Non-Aqueous Electrolyte, Ionic Liquid

\section{Introduction}

Sodium-ion batteries, analogues of lithium-ion batteries by elementary abundant sodium, have intensively been investigated for large scale power sources. Attempts have been made for their positive and negative electrode materials working at ambient temperature. ${ }^{1-23}$ In particular, amorphous carbons such as hard carbon have been recognized to be utilized as negative electrode with similar manner to carbon-based electrodes of lithium-ion batteries. ${ }^{3,7,9-12,15,22}$

In similar manner to reactive sodium metal, the negative electrode at the charged state of sodium inserted electrode is expected to be more reactive than the lithium analogue. Therefore, safety issue should be taken into consideration on practical sodiumion batteries. Presently the solution of sodium perchlorate $\left(\mathrm{NaClO}_{4}\right)$ in propylene carbonate (PC) or other alkylcarbonates have mainly been applied on this purpose. In terms of safety, such electrolytes containing flammable organic solvent should be replaced by sodium-conductor consisting of intrinsically non-flammable components such as ionic liquids. ${ }^{24,25}$ In particular, these having quaternary ammonium cations are stable toward reductive condition such as charged negative electrode. ${ }^{26-28}$

One of major problems of the fundamental investigation on the sodium-ion batteries is the poorer possibility of the selection of adequate chemicals than the case of lithium. For example, sodium bis(trifluoromethane sulfonyl)imide (NaTFSI), being expected to exhibit good solubility and properties, has commercialized most recently. Before that, available sodium salts have very poor solubility into quaternary-ammonium based ionic liquids ${ }^{29}$ except for explosive $\mathrm{NaClO}_{4}$. Under such situation, the present study has been aimed to confirm the influence of the ionic liquid component on the insertion of sodium into hard carbon negative electrode by the observation of its electrochemical behavior in the mixed electrolyte of $\mathrm{NaClO}_{4} / \mathrm{PC}$ with ionic liquid with various mixing ratio. Here $\mathrm{N}, \mathrm{N}$-diethyl-N-methoxyethyl ammonium (DEME) bis(trifluoromethane sulfonyl)imide has been used as ionic liquid species because of its suffucient cathodic stability and miscibility with $\mathrm{NaClO}_{4} / \mathrm{PC}$. The authors believe that such information is still fruitful for the optimum design of ionic liquid-based electrolytes. In addition, the ternary electrolyte $\mathrm{NaClO}_{4} / \mathrm{PC} /$ ionic liquid itself is also expected for less flammable electrolyte, as the ternary solutions of lithium salt/alkylcarbonates/ionic liquid has been investigated for non-flammable electrolytes of lithium-ion batteries. ${ }^{30,31}$

\section{Experimental}

The solution (Kishida Chemical Co., Japan, battery grade) of $1 \mathrm{moldm}^{-3} \mathrm{NaClO}_{4}$ in propylene carbonate (PC) was used as received. The ionic liquid used here was selected to be N,N-diethyl$\mathrm{N}$-methoxyethyl-N-methyl ammonium (DEME) bis(trifluoromethane sulfonyl)imide (TFSI) due to its cathodic stability as shown in previous studies on its utilization to lithium battery electrolytes. The $\mathrm{NaClO}_{4} / \mathrm{PC}$ solution and DEMETFSI ionic liquid were mixed at prescribed ratio in a glove box filled with argon. The solutions of $1 \mathrm{~mol} \mathrm{dm}^{-3} \mathrm{NaClO}_{4} / \mathrm{PC}$ diluted by PC (Kishida, Battery Grade) were also prepared as comparison. The conducitivity of the electrolyte solutions were measured by AC method using a 2-electrode glass cell. Their viscosities were measured by using an Ostwald-type viscometer, in water bath controlled at $30^{\circ} \mathrm{C}$. In order to estimate the solvation state of ions in the electrolyte solutions, Raman spectroscopy (NRS-3100, Nippon Bunko Co., Japan) was carried out. The laser wavelength for Raman measurements was $532 \mathrm{~nm}$.

Hard carbon (Carbotron P, Kureha Chemical Co., Japan) was used as composite electrodes together with poly(vinylidenedifluoride) (PVdF, Kureha Chemical Co.) binder. A slurry solution containing carbon in gravimetric ratio of 0.94 and $\mathrm{PVdF}$ in gravimetric ratio of 0.06 in $\mathrm{N}$-methylpyrrolidinode (Aldrich) was plated on a copper foil ( $20 \mu \mathrm{m}$ in thickness, Nilaco Co., Japan). The sheet was dried under vacuum at $80^{\circ} \mathrm{C}$ during $15 \mathrm{~h}$, and then rollpressed so that the thickness of the carbon-PVdF layer was to be ca. $60 \mu \mathrm{m}$. The electrode sheet was further dried under vacuum at $120^{\circ} \mathrm{C}$ during $24 \mathrm{~h}$ before used in a cell assembly.

A three-electrode beaker cell was assembled with a composite carbon working electrode, a silver wire as a quasi-reference electrode, a platinum plate as a counter electrode, and ca. $2 \mathrm{~cm}^{3}$ of electrolyte, for electrochemical measurement. The cell was assembled in a glove box filled with argon, and placed in a hermetically sealed container. The cyclic voltammetry measurements were conducted at room temperature by using a potentiostat (HZ-3000, Hokuto Denko Co., Japan) under the scan rate of $2 \mathrm{mV} \mathrm{s}^{-1}$ and the potential region between -3.1 and $-1.0 \mathrm{~V}$ vs. Ag. 

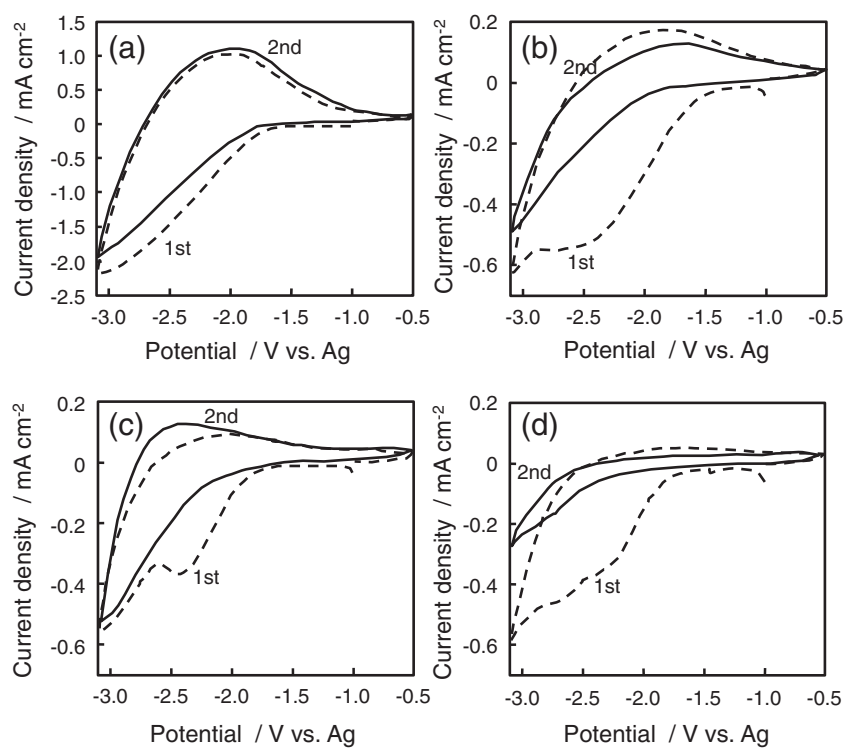

Figure 1. Cyclic voltammograms of hard carbon electrode in $\mathrm{NaClO}_{4} / \mathrm{PC} /$ DEMETFSI mixed electrolytes. Scan rate: $2 \mathrm{mV} \mathrm{s}^{-1}$. Mixed ratio of $\mathrm{NaClO}_{4}\left(1 \mathrm{~mol} \mathrm{dm}^{-3}\right) /$ PC:DEMETFSI (a) 10:0, (b) 5:5, (c) 4:6, (d) 3:7. Dashed line: first cycle, solid line: second cycle.

\section{Results and Discussion}

The cyclic voltammograms of hard carbon electrode in the $\mathrm{NaClO}_{4} / \mathrm{PC} / \mathrm{DEMETFSI}$ mixed electrolytes with various compositions are shown in Fig. 1. The volumetric ratio of $\mathrm{NaClO}_{4} /$ PC:DEMETFSI here is 10:0 (a), 5:5 (b), 4:6 (c) or 3:7 (d). Figure 1(a) is similar to typical voltammogram of lithium or sodium insertion into hard carbon electrode, exhibiting a reversible redox couple of reduction below $-2.0 \mathrm{~V}$ and oxidation above $-2.5 \mathrm{~V}$. This redox couple is assigned to the sodium insertion and extraction from hard carbon electrode. At the first cycle, the reduction current is larger compared with subsequent cycles. On the sodium insertion process, as well as lithium case, the decomposition of electrolyte is considered to occur at the first cycle, and the decomposition product is considered to precipitate on the electrode surface and act as protective film toward further electrolyte decomposition, so-called as solid electrolyte interphase (SEI). The extra reduction current is attributed to the formation process of SEI. The voltammograms in the mixed electrolyte of $\mathrm{NaClO}_{4} / \mathrm{PC}$ with DEMETFSI shown in Figs. 1(b)-1(d) are somewhat different from the case of $\mathrm{NaClO}_{4} /$ $\mathrm{PC}$, and different also by the content of DEMETFSI. In these cases the initial reduction current is larger than the corresponding oxidation current, and the redox currents for subsequent cycles become significantly smaller. The appearance of oxidation current is dependent on the content of DEMETFSI. The voltammogram in the mixed electrolyte with the ratio $\mathrm{NaClO}_{4} / \mathrm{PC}$ :DEMETFSI of 5:5 or 4:6 shows oxidation current. In contrast, such oxidation current is not observable in the voltammogram in the electrolyte $\mathrm{NaClO}_{4} / \mathrm{PC}$ : DEMETFSI $=3: 7$. These voltammetric behaviors indicate that the coexistence of DEMETFSI in the $\mathrm{NaClO}_{4}$ electrolyte inhibits the sodium insertion into hard carbon at some extent. In the electrolytes containing DEMETFSI, the initial reduction current flows at similar extent to the case of $\mathrm{NaClO}_{4} / \mathrm{PC}$, while the oxidation peak and subsequent redox current decreases.

At the first glance when considering the reason of the difference of the voltammetric behavior in $\mathrm{NaClO}_{4} / \mathrm{PC} /$ DEMETFSI from that in $\mathrm{NaClO}_{4} / \mathrm{PC}$, the influence of the concentration of sodium ion by the mixing with DEMETFSI should be discussed at first. Thus the dependence of sodium concentration in electrolyte on the sodium insertion behavior has been estimated by the comparison with
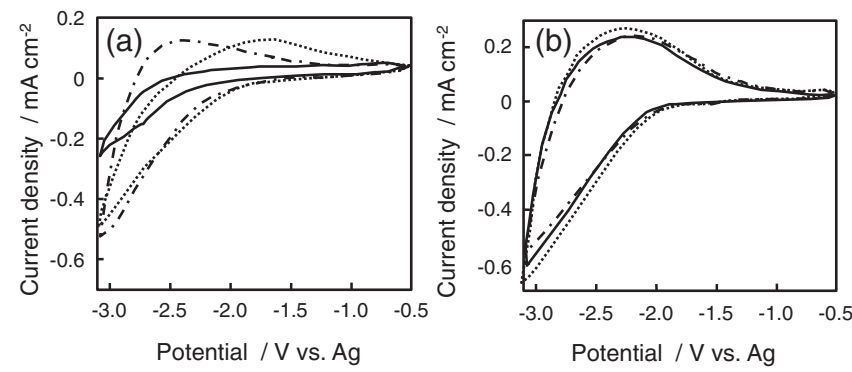

Figure 2. Cyclic voltammograms at second cycles of hard carbon electrode in $\mathrm{NaClO}_{4} / \mathrm{PC} /$ DEMETFSI mixed electrolytes. Scan rate: $2 \mathrm{mV} \mathrm{s}^{-1}$. (a) $\mathrm{NaClO}_{4} / \mathrm{PC} /$ DEMETFSI electrolytes by the ratio $\mathrm{NaClO}_{4}\left(1 \mathrm{~mol} \mathrm{dm}^{-3}\right) /$ PC:DEMETFSI of 5:5 (dotted line), 4:6 (dashed line), and $3: 7$ (solid line). (b) $\mathrm{NaClO}_{4} / \mathrm{PC}$ by the ratio $\mathrm{NaClO}_{4}\left(1 \mathrm{~mol} \mathrm{dm}^{-3}\right) / \mathrm{PC}: \mathrm{PC}$ of 5:5 (dotted line), 4:6 (dashed line), and 3:7 (solid line).

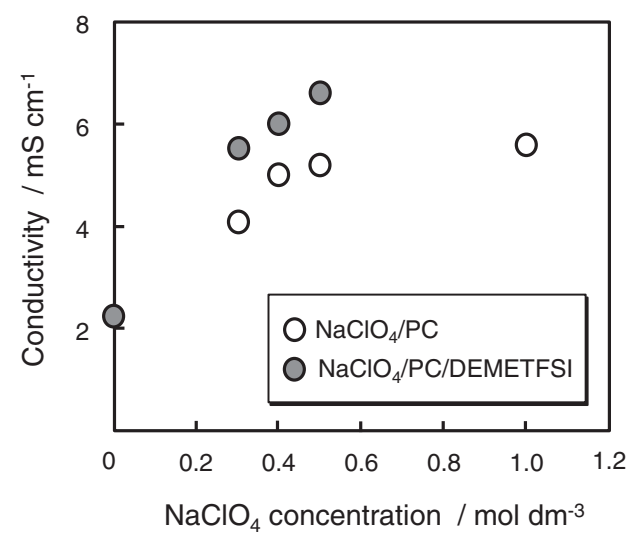

Figure 3. Plots of conductivity of $\mathrm{NaClO}_{4} / \mathrm{PC}$ and $\mathrm{NaClO}_{4} / \mathrm{PC} /$ DEMETFSI electrolytes by the concentration of $\mathrm{NaClO}_{4}$. Temperature: $298 \mathrm{~K}$.

diluted $\mathrm{NaClO}_{4} / \mathrm{PC}$ solution. Figure 2 shows voltammograms at the second cycle for the hard carbon electrode in $\mathrm{NaClO}_{4} / \mathrm{PC}$ (a) and $\mathrm{NaClO}_{4} / \mathrm{PC} /$ DEMETFSI (b) at various $\mathrm{NaClO}_{4}$ concentrations, that is, various mixing ratios of $\mathrm{NaClO}_{4} / \mathrm{PC}$ and DEMETFSI or PC. The $\mathrm{NaClO}_{4} / \mathrm{PC}$ electrolyte system provides similar voltammogram with reversible sodium insertion regardless of the $\mathrm{NaClO}_{4}$ concentration. In contrast, as mentioned in the previous section, the reversible sodium insertion is depressed by the increase of the content of DEMETFSI from Fig. 2(b). This difference in voltammetric behavior indicates that the decrease in $\mathrm{NaClO}_{4}$ concentration is not the reason for the inhibition of reversible sodium insertion by the coexistence of DEMETFSI.

The coexistence of DEMETFSI in $\mathrm{NaClO}_{4} / \mathrm{PC}$ electrolyte is not due to the decrease of concentration of sodium salt in the electrolyte, but due to the decrease of its 'effective' concentration. In other words, the coordination state of sodium ion is considered to be different between $\mathrm{NaClO}_{4} / \mathrm{PC}$ and $\mathrm{NaClO}_{4} / \mathrm{PC} /$ DEMETFSI systems. The coordination state of sodium ion may reflect to the ionic conductivity of these electrolytic solutions. Also, the interaction mode between ions has been attempted to be monitored with Raman spectroscopy.

The ionic conductivities at ambient temperature of the $\mathrm{NaClO}_{4} /$ PC/DEMETFSI mixed electrolytes together with $\mathrm{NaClO}_{4} / \mathrm{PC}$ electrolytes are plotted toward the concentration of $\mathrm{NaClO}_{4}$ in Fig. 3. The conductivity of $\mathrm{NaClO}_{4} / \mathrm{PC}$ electrolyte increases by the rise of concentration at the concentration region between 0.3 and $0.5 \mathrm{~mol} \mathrm{dm}^{-3}$, corresponding to the mixing ratio of $\mathrm{NaClO}_{4} / \mathrm{PC}: \mathrm{PC}$ of 3:7 and 5:5, respectively. This conductivity increase suggests that the formation of ion pair between $\mathrm{Na}^{+}$and $\mathrm{ClO}_{4}{ }^{-}$is not major and 


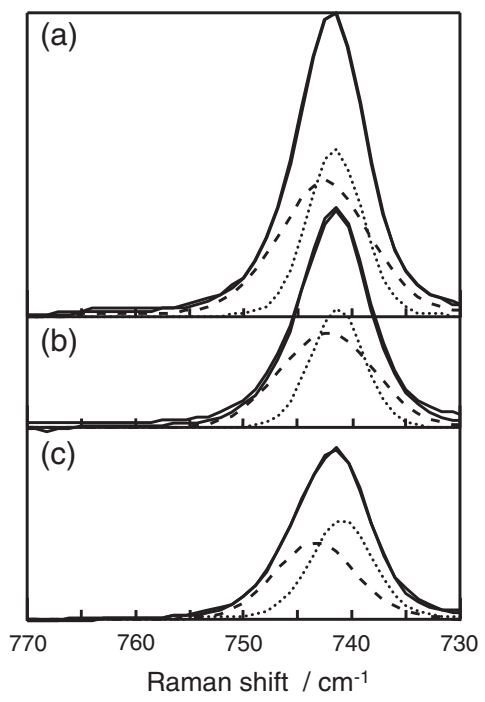

Figure 4. Raman spectra magnified at 730 to $770 \mathrm{~cm}^{-1}$ with peak separation results. (a) DEMETFSI, (b) PC:DEMETFSI (3:7), (c) $\mathrm{NaClO}_{4} /$ PC:DEMETFSI (3:7).

$\mathrm{Na}^{+}$is mainly solvated by $\mathrm{PC}$ at these compositions. The conductivities of the $\mathrm{NaClO}_{4} / \mathrm{PC} /$ DEMETFSI electrolytes are larger than those of $\mathrm{NaClO}_{4} / \mathrm{PC}$ systems, mainly due to the larger number of ions. The conductivity of the $\mathrm{NaClO}_{4}$ /PC/DEMETFSI system increases also by the increase of the content of $\mathrm{NaClO}_{4}$, together with $\mathrm{PC}$, even though the number of ion decreases. Such conductivity change appears to be related to the decrease of viscosity, ca. 11 and $6.5 \mathrm{mPa}$ for 3:7 and 5:5 solutions, respectively. The precise status of ion-ion interaction in the $\mathrm{NaClO}_{4} / \mathrm{PC} / \mathrm{DEMETFSI}$ systems is unclear from the comparison of conductivities.

Raman spectra around $741 \mathrm{~cm}^{-1}$ and the calculation results of peak separation for the $\mathrm{NaClO}_{4} / \mathrm{PC} /$ DEMETFSI electrolytes are shown in Fig. 4. Raman spectra for bare DEMETFSI and the mixture of PC and DEMETFSI at the ratio of 3:7 are included as comparison. The peak at $741 \mathrm{~cm}^{-1}$ is assigned to the symmetric deformation mode of $\mathrm{CF}_{3}$ - from TFSI anion, and shows peak split at higher frequency direction by the formation of ion pair. ${ }^{32}$ These peaks observed here have a shoulder peak at higher frequency, thus peak separation is carried out using the software attached with Raman spectrometer apparatus. The results of peak separation are also included in Fig. 4. The low frequency fraction observed in all the spectra is assigned to 'free' TFSI anion, and the high frequency fraction may be the contribution of the ion-paired TFSI. The feature of peak separation for the PC/DEMETFSI is similar to that for bare DEMETFSI, free TFSI and ion-paired fraction peaked at $742.5 \mathrm{~cm}^{-1}$. In such cases TFSI forms ion pair with DEME cation. In contrast, the high frequency fraction is shown at different position, $743.5 \mathrm{~cm}^{-1}$, for the $\mathrm{NaClO}_{4} / \mathrm{PC} / \mathrm{DEMETFSI}$ electrolytes. Such difference in peak position is possibly due to the difference of coordinated species. In other words, when $\mathrm{NaClO}_{4}$ coexists in the electrolyte solution, the ion pair between $\mathrm{Na}^{+}$and $\mathrm{TFSI}^{-}$is significantly formed. The amount of Na-TFSI interaction is considered to increase gradually by the increase of the content of DEMETFSI.

The mechanisms of lithium ion insertion into various kinds of electrodes have been proposed. Abe et al. have claimed that the ratedetermining process of electrochemical intercalation of lithium ion is de-solvation process of lithium ion regardless of the intercalation host electrode. ${ }^{33-35}$ Also for the case of sodium ion insertion into hard carbon, the de-solvating of sodium ion is expected to play an important role. On the mixed electrolyte of $\mathrm{NaClO}_{4} / \mathrm{PC}$ and DEMETFSI, the inhibition of sodium ion insertion may be contributed by the change of the solvation state of sodium ion. The Na-TFSI ion-pair is considered to provide the negative impact gradually by the increase of TFSI anion, as indicated by the relative degradation observed in the voltammograms in the electrolytes containing 50 or $60 \%$ of DEMETFSI compared with the case of $\mathrm{NaClO}_{4} / \mathrm{PC}$. Such the impact may be dominant on the electrode/ electrolyte interface in the electrolyte containing $70 \%$ and may relate to the diminishment of the redox current on the voltammogram. In addition, the different solvation of sodium ion may also provide different surface film on the hard carbon electrode, and inhibit the insertion by passivating.

One can consider that the coexistence of DEMETFSI changes the composition of surface film on the hard carbon and thus changes the electrochemical behavior directly. However, the authors have assumed that the influence of the composition change of the surface film is rather minor because the change in electrochemical behavior has been observed at the intermediate mixing ratio of $\mathrm{NaClO}_{4}$ / PC:DEMETFSI to 3:7.

The non-flammability is expected to enhance with the increase of the content of ionic liquid from previous report of mixed electrolyte for lithium-ion batteries. In the present case of the ternary electrolyte of $\mathrm{PC} / \mathrm{NaClO}_{4} / \mathrm{DEMETFSI}$, the compatibility with negative electrode may contradict to the non-flammability. ${ }^{31}$ In terms of practical usage, the electrolyte containing $50 \%$ of DEMETFSI appears to be attractive among this series due to somewhat improved non-flammability, compatibility with hard carbon electrode, and relatively high conductivity.

\section{Conclusion}

The coexistence of DEMETFSI ionic liquid in the $\mathrm{NaClO}_{4} / \mathrm{PC}$ electrolyte tends to inhibit the insertion of sodium into hard carbon electrode. In particular, the oxidation current becomes obvious when the content of DEMETFSI is over $70 \mathrm{vol} \%$. The coexistence of DEMETFSI into $\mathrm{NaClO}_{4} / \mathrm{PC}$ changes the coordination state of sodium ion, that is, TFSI anion participates in the coordination to sodium ion. Such the change of coordination state of sodium ion may contribute to the inhibition effect of sodium insertion. These results comprise the difficulty of the sodium insertion in binary electrolyte sodium salt/ionic liquid having TFSI anion without any modifier of coordination state of sodium ion. Further study is required in order to clarify the relationship between the status of sodium ion and the insertion of sodium in these ternary electrolytes.

\section{Acknowledgment}

The present study is a part of research project of Ministry of Education, Culture, Sport, Science and Technology "Element Science and Technology Project".

\section{References}

1. M. Abraham, Solid State Ionics, 7, 199 (1982).

2. C. Delmas, F. Cherkaoui, A. Nadiri, and P. Hagenmuller, Mater. Res. Bull., 22, 631 (1987).

3. M. M. Doeff, Y. Ma, S. J. Visco, and L. C. de Jonghe, J. Electrochem. Soc., 140, L169 (1993).

4. M. M. Doeff, S. J. Visco, Y. Ma, M. Peng, L. Ding, and L. C. de Jonghe, Electrochim. Acta, 40, 2205 (1995).

5. J. Morales, J. Santos, and J. L. Tirado, Solid State Ionics, 83, 57 (1996).

6. I. Saadoune, A. Maazaz, M. Ménétrier, and C. Delmas, J. Solid State Chem., 122, 111 (1996).

7. D. A. Stevens and J. R. Dahn, J. Electrochem. Soc., 147, 1271 (2000).

8. L. Su, J. Winnick, and P. Kohl, J. Power Sources, 101, 226 (2001).

9. R. Alcántara, J. M. Jiménez-Mateos, P. Lavela, and J. L. Tirado, Electrochem. Commun., 3, 639 (2001).

10. R. Alcántara, M. Jaraba, P. Lavela, and J. L. Tirado, Chem. Mater., 14, 2847 (2002).

11. R. Alcántara, J. M. Jiménez Mateos, and J. L. Tirado, J. Electrochem. Soc., 149, A201 (2002).

12. P. Thomas and D. Billaud, Electrochim. Acta, 47, 3303 (2002). 
13. J. Barker, M. Y. Saidi, and J. L. Swoyer, Electrochem. Solid-State Lett., 6, A1 (2003).

14. Y. Uebou, S. Okada, and J. Yamaki, J. Power Sources, 115, 119 (2003).

15. R. Alcántara, P. Lavela, G. F. Ortiz, and J. L. Tirado, Electrochem. Solid-State Lett., 8, A222 (2005).

16. J. Barker, R. K. B. Gover, P. Burns, and A. J. Bryan, Electrochem. Solid-State Lett., 9, A190 (2006).

17. T. Shiratsuchi, S. Okada, J. Yamaki, and T. Nishida, J. Power Sources, 159, 268 (2006).

18. T. B. Kim, J. W. Choi, H. S. Ryu, G. B. Cho, K. W. Kim, J. H. Ahn, K. K. Cho, and H. J. Ahn, J. Power Sources, 174, 1275 (2007).

19. I. Gocheva, M. Nishijima, T. Doi, S. Okada, and J. Yamaki, J. Power Sources, 187, 247 (2009)

20. N. Recham, J. N. Chotard, I. Dupont, K. Djellab, M. Armand, and J. M. Tarascon, J. Electrochem. Soc., 156, A993 (2009).

21. S. Komaba, C. Takei, T. Nakayama, A. Ogata, and N. Yabuuchi, Electrochem. Commun., 12, 355 (2010).

22. S. Komaba, W. Murata, T. Ishikawa, N. Yabuuchi, T. Ozeki, T. Nakayama, A. Ogata, K. Gotoh, and K. Fujiwara, Adv. Funct. Mater., 21, 3859 (2011).

23. R. Hagiwara, T. Nohira, A. Fukunaga, S. Sakai, K. Nitta, and S. Inazawa, Electrochemistry, 80, 98 (2012). [in Japanese]
24. A. Fernicola, B. Scrosati, and H. Ohno, Ionics, 12, 95 (2006).

25. A. Lewandowski and A. Świderska-Mocek, J. Power Sources, 194, 601 (2009).

26. P. C. Howlett, D. R. MacFarlane, and A. F. Hollenkamp, Electrochem. Solid-State Lett., 7, A97 (2004).

27. H. Sakaebe and H. Matsumoto, Electrochem. Commun., 5, 594 (2003).

28. T. Sato, T. Matsuo, S. Marukane, and K. Takagi, J. Power Sources, 138, 253 (2004).

29. M. Egashira, T. Asai, N. Yoshimoto, and M. Morita, Electrochim. Acta, 58, 95 (2011).

30. A. Chagnes, M. Diaw, B. Carré, P. Willmann, and D. Lemordant, J. Power Sources, 145, 82 (2005).

31. H. Nakagawa, Y. Fujino, S. Kozono, Y. Katayama, T. Nukuda, H. Sakaebe, H. Matsumoto, and K. Tatsumi, J. Power Sources, 174, 1021 (2007).

32. Z. Wang, W. Gao, X. Huang, Y. Mo, and L. Chen, Electrochem. Solid-State Lett., 4, A148 (2001).

33. T. Abe, H. Fukuda, Y. Iriyama, and Z. Ogumi, J. Electrochem. Soc., 151, A1120 (2004).

34. T. Doi, K. Miyatake, Y. Iriyama, T. Abe, Z. Ogumi, and T. Nishizawa, Carbon, 42, 3183 (2004)

35. T. Doi, Y. Iriyama, T. Abe, and Z. Ogumi, J. Power Sources, 142, 329 (2005). 